\title{
Imagem e conhecimento o uso de recursos didáticos visuais nas aulas de Sociologia
}

\author{
Image and knowledge \\ the use of visual didactic resources in Sociology classes
}

Lisandro Lucas de Lima Moura ${ }^{1}$

\section{RESUMO}

O trabalho busca compreender a utilização de recursos didáticos visuais (fotografias, vídeos, filmes, documentários, pinturas etc.) nas aulas de Sociologia no Ensino Médio. O objetivo é saber de que modo esses instrumentos podem contribuir para a compreensão da sociedade, e em que medida essa compreensão está baseada no pensamento crítico, uma das finalidades da Sociologia na escola. Através de entrevistas com professores(as) de Sociologia de escolas de nível médio do Brasil, observamos a dificuldade dos(as) professores(as) em desenvolver uma reflexão mais consistente do ponto de vista metodológico e sociológico, de modo a possibilitar a construção do conhecimento através das imagens, para além da simples transmissão de conteúdos e temas curriculares. O conhecimento produzido pelo campo da Sociologia Visual pode vir a enriquecer a experiência pedagógica dos(as) professores(as) e possibilitar o exercício da imaginação mediante a educação do olhar.

Palavras-chave: Imagem e conhecimento. Ensino de Sociologia. Educação do olhar. Sociologia visual.

\section{ABSTRACT}

This work aims to understand the use of visual didactic resources (photos, videos, movies, documentaries, pictures, etc) in High School Sociology classes. The objective is to learn how such tools can contribute to understand society, as well as in what extent this understanding is based on critical thought, one of the goals of teaching Sociology in school. Through interviews with Sociology teachers from Brazilian high schools, we have also noticed that teachers have trouble developing a more consistent reflection from both methodological and sociological viewpoints, so that it makes the knowledge building through images possible. Knowledge built by Visual Sociology can improve the pedagogical experiences of teachers and enable the exercise of imagination through the education of sight.

Key-words: Image and knowledge. Sociology teaching. Education of sight. Visual Sociology.

\footnotetext{
1 Mestrando do Programa de Pós-Graduação em Educação da Universidade Federal de Pelotas (UFPel). Bacharel e Licenciado em Ciências Sociais pela Universidade Federal do Rio Grande do Sul (UFRGS). Professor de Sociologia do Instituto Federal de Educação, Ciência e Tecnologia Sul-riograndense (IFSul-Campus Bagé). lisandromoura@ifsul.edu.br
} 


\section{INTRODUÇÃO}

O presente trabalho busca investigar metodologias de ensino para a disciplina de Sociologia no Ensino Médio, pautadas no uso de recursos visuais: fotografias, filmes, vídeos, documentários e pinturas. A relação entre imagem, conhecimento e ensino revelou-se como o principal problema abordado nesta pesquisa, fruto das minhas inquietações como professor de Sociologia na educação básica, o que me levou a estudar o tema atentamente durante meu Trabalho de Conclusão de Curso em Ciências Sociais pelo Instituto de Filosofia e Ciências Humanas da Universidade Federal do Rio Grande do Sul - UFRGS, sob orientação da Professora Dr. ${ }^{a}$ Luiza Helena Pereira. (MOURA, 2010).

A pesquisa buscou identificar os usos da imagem em sala de aula, bem como os problemas de ordem metodológica, teórica e epistemológica encontrados pelos professores e professoras de Sociologia da educação básica quando da utilização destes recursos. Mais do que isso, os artefatos imagéticos revelaram-se de grande importância para a compreensão do mundo social contemporâneo, marcado por uma intensa visualidade que ganha status de algo natural e desprovida de historicidade e disputas ideológicas.

Dessa forma, a intenção deste trabalho é indicar a importância das imagens para a construção do conhecimento sociológico, já que estamos trabalhando com uma disciplina que recentemente se tornou obrigatória nos currículos de todas as escolas do Brasil $^{2}$, e que através dela milhares de jovens terão algum tipo de relação com o modo sociológico de pensar. E com isso, surgem algumas perguntas: é possível conhecer a realidade social a partir de uma simples fotografia? De que forma? E que tipo de conhecimento ela nos propõe? Quais as relações possíveis entre imagem e realidade social? Como utilizar as imagens em sala de aula desde uma perspectiva criativa e sensível para os alunos, e que ao mesmo tempo possibilite um conhecimento crítico do viver social? A partir destes questionamentos, percebemos que existem várias formas de tentar respondê-los, e as Ciências

\footnotetext{
${ }^{2}$ Parecer CNE/CEB 38/2006. Lei $n^{\circ} 11.684$, de 02 de junho de 2008 que altera o Art. 36 da Lei no 9.394, de 20 de dezembro de 1996, que estabelece as diretrizes e bases da educação nacional, para incluir a Filosofia e a Sociologia como disciplinas obrigatórias nos currículos do ensino médio.
} 
Sociais já há um bom tempo vem tentando fazê-lo, trilhando novos caminhos para a maior compreensão das sociedades a partir de referenciais imagéticos.

Foi feito um levantamento dos principais recursos didáticos visuais e audiovisuais utilizados pelos(as) professores(as) mediante metodologia qualitativa, com entrevistas semi-estruturadas. Foram entrevistados(as) dez professores(as) de Sociologia de algumas escolas do País que fazem uso de imagens em suas aulas. Parte das entrevistas foi aplicada durante a realização do I Encontro Nacional sobre o Ensino de Sociologia na Educação Básica, realizado pela SBS (Sociedade Brasileira de Sociologia), na Universidade Federal do Rio de Janeiro (UFRJ), em 2009, e, portanto, abrange professores e professoras de diferentes localidades do Brasil (São Paulo, Palmas, Abaetetuba, Bento Gonçalves, Santa Maria, Porto Alegre, dentre outras regiões). Além disso, nesse mesmo espaço aconteceu a Oficina Imagem e Ensino de Sociologia, coordenada pela professora. Ana Lucia Lucas Martins (UFRJ) e pelo professor. Amaury César Moraes (USP). A Oficina serviu de campo de observação das discussões conceituais e métodos de utilização de imagens por professores(as) da educação básica.

Antes de compreendermos o significado que as imagens adquirem na prática pedagógica dos(as) professores(as) de Sociologia, a fim de responder às indagações feitas nesta pesquisa, é necessário conhecermos algumas tendências recentes das Ciências Sociais que se utilizam dos métodos visuais para análise do conjunto das relações sociais, bem como as dificuldades analíticas decorrentes dessa abordagem. O conhecimento produzido pelo campo da Sociologia Visual é de fundamental importância para qualificarmos as práticas pedagógicas, tanto no Ensino Médio quanto no Ensino Superior.

\section{VER PRECEDE AS PALAVRAS: POR UMA EDUCAÇÃO DO OLHAR}

Olhar é um ato de escolha. John Berger

Vemos con los ojos. Ao apresentar as peculiaridades do olho sociológico, o espanhol Jesus de Miguel (2003) afirma que para poder ver não é necessário uma aprendizagem específica, mas que para ver bem, com olhar sociológico, a 
aprendizagem se torna necessária, e pode ser conquistada mediante o processo de reeducação do olhar, sob responsabilidade dos cursos de Ciências Sociais das universidades (MIGUEL, 2003, p.50) e, também, das escolas onde a disciplina de Sociologia está em processo de consolidação.

Cabe ressaltar desde já que não é nenhuma novidade referir-se ao mundo visual como método e conteúdo das pesquisas sociológicas e antropológicas. Silvia Caiuby Novaes (apud HIKIJI, 2005) apresenta fortes indícios da tradição visual das ciências sociais até mesmo no vocabulário com que comumente estamos familiarizados, e que contem, segundo ela, uma linguagem visual bastante clara: "observação", "ponto de vista", "visão de mundo", "perspectivas", "evidências", "ótica", "olhar" etc. (NOVAES apud HIKIJI, 2005, p.273). Ulpiano Bezerra de Meneses (2005) também se refere à assimilação do conhecimento a partir da visualização, referindo-se ao oculocentrismo como "privilegiamento epistemológico da visão, cuja hegemonia caracteriza a modernidade." (MENESES, 2005, p.36). Esse autor, valendo-se da expressão de José de Souza Martins (1996), ditadura do olho, afirma que, muitas vezes, essa hegemonia da visão acaba por repelir outras dimensões da experiência e do vivido. (MENESES, 2005). Ou ainda, a expressão de Jesus de Miguel, "la realidad social entra por los ojos", buscando, com ela, justificar a necessidade da utilização da fotografia, da imagem virtual, do cinema, do vídeo para o conhecimento da realidade social, uma vez que, segundo o autor, o século XXI é o século da imagem (idem, p.50).

Mesmo sabendo que grande parte do que conhecemos no mundo se dá pelo visual, pelo olho, mesmo assim, parece que a visualidade do mundo social carece de ser tratada como objeto de estudo que deve ser priorizado, do ponto de vista metodológico, nas ciências sociais. Parece que até o momento os pesquisadores e pesquisadoras em ciências sociais "deram maior importância para a construção social do visível, sem levar em conta também a construção visível do social" (MENESES, 2005, p.50), ou seja, a forma pela qual a sociedade se mostra, a representação imagética de si, enquanto objeto de conhecimento da vida social. Trata-se, portanto, de levar em conta a especificidade da imagem, pois ela requer um modo próprio de análise, conforme nos indica o autor, valendo-se da citação do historiador Arthur Freitas: 
não é apenas o ambiente sócio-cultural que pode aguçar nossa experiência de uma imagem artística, mas, revertendo a equação, que as próprias formas e os estilos visuais também podem 'apurar a percepção que temos da sociedade. (FREITAS apud MENESES, 2005, p.42)

Ainda que seja possível verificar uma vasta literatura em ciências humanas dedicada ao estudo da imagem por parte de alguns pensadores(as) importantes, dentre eles(as) Howard Becker ${ }^{3}$ (1996), Pierre Francastel (1987), Susan Sontag (2004), Jacques Aumont (1993) e Roland Barthes (1990), entre outros, o que tudo indica é que a teoria sociológica da imagem não se desenvolveu plenamente e ainda não ganhou espaço significativo no conjunto da produção intelectual da área.

Conforme Koury (1998), é recente no Brasil a produção científica que leva em consideração a imagem como objeto específico de investigação sociológica ${ }^{4}$.

A pesquisa visual nas Ciências Sociais, de qualquer forma, parece indicar um campo ainda em definição, sem fronteiras delimitadas, onde o pesquisador ainda caminha sem muita clareza: às vezes situando-se em aspectos ligados estritamente à problemática das linguagens em imagens, às vezes usando as imagens como simples ilustração de um texto verbal. (KOURY, 1998, p.9192)

Tanto na Sociologia como na Antropologia, afirma o autor, "as imagens eram tidas como registro do real, como uma leitura exemplar do real" (KOURY, 1999, p.50). Assim, não havia uma preocupação analítica sobre a utilização da imagem. A fotografia, que até então esteve presente em inúmeros trabalhos na área das ciências sociais brasileiras ${ }^{5}$, servia simplesmente de "prova do real analisado ou mesmo de prova da presença do autor no local estudado, como que para dar veracidade à análise realizada" (idem, p.50). Veremos adiante as relações possíveis entre imagem e realidade, mas queremos adiantar, desde já, que essa postura imprecisa de trabalhar as imagens como sendo reprodução da realidade vem sendo frequentemente contestada nos trabalhos mais recentes da Sociologia (e da Antropologia) da Imagem (MARTINS, 2005 e 2008b; MENEZES, 2003 e 2005).

\footnotetext{
${ }^{3}$ Becker é certamente o sociólogo que mais escreveu sobre fotografia entre os anos 1974 e 1986. (MIGUEL; LEÓN, 1998)

4 "A Antropologia Visual ganha, assim, espaço prioritário como fundamentação do locus das pesquisas em Imagem nas Ciências Sociais em torno do seu nome. É onde se tem, de modo mais avançado, uma discussão - embora ainda tênue, mas que ganha força a cada movimento - sobre a necessidade de delimitação das fronteiras disciplinares teórico-metodológicas". (KOURY, 1998, p.94)

5 "Exemplo disso são os trabalhos de Roger Bastide, Gilberto Freire e de tantos outros que se valiam da fotografia nos seus trabalhos como suporte a mais à análise verbal de suas teses." (KOURY, 1999, p.50)
}

Cad. de Pesq. Interdisc. em Ci-s. Hum-s., Florianópolis, v.12, n.100, p.159-182, jan/jul 2011 
Na Espanha, temos como referência o já citado sociólogo Jesus de Miguel (1998), que se dedica a construir um campo fértil da Sociologia Visual espanhola e latino-americana, atuando como membro do International Visual Sociology Asssociation $^{6}$. Por isso o seu trabalho foi de extrema importância para esta pesquisa. Segundo o espanhol,

\begin{abstract}
Muy pocas tesis doctorales o investigaciones en las ciencias sociales incluyen texto y fotos a un nivel de igualdad. Si lo hacen es a un nivel desequilibrado de importancia. Las fotos, pocas, suelen ser una mera ilustración del texto. No se suele desarrollar una teoría con imágenes. (MIGUEL, 1998, p.85).
\end{abstract}

Conforme Koury (1999), só a partir dos anos oitenta que as imagens ganham um espaço mais importante de documentação nas ciências sociais do Brasil.

Em suma, os anos setenta e oitenta trouxeram para o pesquisador
brasileiro em ciências sociais uma consciência mais clara do valor do
documento imagético para a análise do fenômeno social, levando-o a
debruçar-se sobre imagens, a preocupar-se com o registro imagético e,
ainda, a buscar mais sistematicamente a organização de acervos de
imagens cuja utilização pudesse ir além da demanda por um trabalho
específico de um determinado autor. (KOURY, 1999, p.51).

O autor cita o Núcleo de Antropologia Visual (Navisual) ${ }^{7}$, da Universidade Federal do Rio Grande do Sul (UFRGS), como o mais antigo em termos de desenvolvimento de trabalhos sistemáticos com imagens no Brasil. O Navisual surgiu no final da década de oitenta, como Laboratório de Antropologia Visual e, logo a seguir, no início dos anos noventa, ganhou status de núcleo. (RODOLPHO apud KOURY, 1999, p.52) ${ }^{8}$.

Se o próprio campo das ciências sociais visuais é ainda incipiente, como ficam os(as) professores(as) de Sociologia da educação básica, que a todo momento se utilizam de recursos alternativos como métodos de aprendizagens com seus alunos? Como a Sociologia pode contribuir com a especificidade do seu olhar para o trabalho com as imagens e os recursos audiovisuais na escola, inclusive servindo de referência para professores(as) de outras áreas do conhecimento?

\footnotetext{
${ }^{6}$ A International Visual Sociology Association é uma associação profissional e acadêmica dedicada ao estudo visual da sociedade, da cultura e das relações sociais. Tem como objetivo potencializar o uso da imagem em pesquisas de diversas áreas do conhecimento: Sociologia, Antropologia, Educação, Pedagogia, Comunicação, Arte, Fotografia, Jornalismo etc. (http://www.visualsociology.org/).

7 http://www6.ufrgs.br/ppgas/nucleos/navisual/

8 Caso haja interesse em conhecer outros Núcleos, Laboratórios e Grupos de Pesquisa de ciências sociais e imagem existentes atualmente, basta acessar o link do Grupo de Trabalho de Antropologia Visual da Associação Brasileira de Antropologia: http://antropologiavisualaba.blogspot.com/
} 


\section{O OLHAR ILUDIDO: A PROPÓSITO DA REALIDADE DA IMAGEM E A IMAGEM DA REALIDADE}

A Map is not the Territory, and the Name is not the thing named Alfred Korzybski

$\mathrm{Na}$ literatura produzida pelas Ciências Sociais da Imagem, percebe-se a existência de controvérsias sobre as relações entre realidade e imagem. Em que sentido a imagem pode ser um instrumento de análise da vida social? Será que aquilo que vemos em uma fotografia ou em um filme documental ou ficcional pode dizer muito sobre a realidade social? De que forma? E mais: o que é a "realidade" e o que é o "real"? Muitas dessas indagações foram e ainda estão sendo feitas por diversos pesquisadores e pesquisadoras, que citaremos adiante, e que encontram na imagem uma fonte para se saber como vive o ser humano.

A relação entre Sociologia e imagem envolve questões bastante complexas. Dificilmente os pesquisadores que se utilizam dela conseguem dar conta de sua especificidade. Muitas vezes, como nos lembra Ulpiano Bezerra de Meneses, ela é

\footnotetext{
convertida em tema e tratada como fornecedora de informações redutíveis a um conteúdo verbal. Ou então considerada como ponte inerte entre as mentes de seus produtores e os observadores, ou mesmo, no geral, entre práticas e representações. Ou ainda, o que é pior - mas já está suficientemente denunciado - considerada como apta a desempenhar tão somente função ilustrativa. (MENESES, 2005, p.40)
}

O que mais inquieta cientistas sociais e historiadores da imagem é justamente o poder de evidência que a imagem apresenta, ou seja, o poder de confundir-se com o real. Merleau-Ponty dedicou-se ao estudo do cinema e evidenciou o realismo a ele inerente.

O cinema falado, com seu diálogo amiúde envolvente, completa nossa ilusão. Daí, concebe-se muitas vezes o filme como sendo a representação visual e sonora, a reprodução mais fiel e possível de um drama, o qual a literatura só poderia sugerir com palavras, enquanto o cinema tem a sorte de poder fotografar. O equívoco se mantém porque existe, deveras, um realismo fundamental pertinente ao cinema. (MERLEAU-PONTY, apud MENEZES, 2004, p.32)

O crítico francês André Bazin (1991), além de ser um dos mais conceituados teóricos de cinema, é o mais notável representante da vertente realista. Ele acredita 
que a objetividade da imagem fotográfica não abre espaço para a imaginação no ato fotográfico.

A originalidade da fotografia em relação à pintura reside, pois, na sua objetividade essencial. Tanto é que o conjunto de lentes que substitui o olho fotográfico em substituição ao olho humano denomina-se precisamente "objetiva". Pela primeira vez entre o objeto inicial e sua representação nada se interpõe, a não ser um outro objeto. Pela primeira vez, uma imagem do mundo exterior se forma, automaticamente, sem a intervenção criadora do homem. (BAZIN, 1991, p.22).

Com isso, Bazin chama a atenção para a crença do espectador na fidelidade da imagem fotográfica, que se constrói a partir das técnicas realistas da fotografia e do cinema. Esse poder de convencimento que têm o cinema e a fotografia, principalmente, mas também as imagens no sentido geral, confunde o espectador e, por que não, o professor-sociólogo ingênuo. Isso torna instigante a análise de imagens. Porque tanto o espectador comum quanto o professor e o cientista social raramente vão ao cinema pensando criticamente na irrealidade das imagens, em distingui-las entre cenas reais e montagens, ou seja, pensando no fato de que elas são apenas uma representação do real e não a realidade propriamente ${ }^{9}$. Conforme Barthes (1990), "é bem verdade que a imagem não é o real, mas é, pelo menos, o seu analogon perfeito." (p.12). Assim, devemos levar em conta a "impressão de verdade" (SORLIN apud MENEZES 2004, p.32) que a imagem produz no espectador.

O conceito de representificação, desenvolvido por Menezes (2003), ao invés de representação, é importante para dar conta da complexidade da análise sociológica da imagem. O autor atenta para o fato de que o conceito de representação designa algo diferente do real, da coisa em si. A representação de qualquer coisa é a criação de outra coisa. Nesse sentido, se a imagem é representação do real, como explicar o seu poder de evidência, o seu poder de confundir-se com o real, já que representação seria algo diferente do real? Segundo Menezes (2003), o poder de evidência da imagem não pode ser "superado por uma mera operação intelectual, por um ato da 'consciência'. Por isso, a imagem não é uma representação do real, pois a representação não se confunde com o próprio real”. (MENEZES, 2003, p.94). Ou seja, o que a imagem apresenta não é o que é

\footnotetext{
${ }^{9}$ Tomemos como exemplo os inúmeros casos em que a pessoa, ao assistir a novela na televisão, muitas vezes, confunde 0 ator com o personagem. Segundos relatos de atores de novela, estes chegam a ser "insultados" na rua pelo fato de seu personagem, na ficção, ser um vilão que contraria as expectativas do público.
} 
visto, mas isso não está claro para o espectador porque a imagem possui um poder de convencimento. Por isso, conforme Menezes (2003), ela não pode ser uma "representação" do real, mas uma representificação, ou seja, algo que nos "coloca em presença de relações mais do que numa presença de fatos e coisas" (idem, p.94). Relações estas constituídas pela história de determinada imagem, "entre o que ela mostra e o que ela esconde". (idem, p.94).

Ainda segundo Menezes (2004), Walter Benjamin já alertava, em A Pequena História da Fotografia, que "a natureza que fala à câmera não é a mesma que fala ao olhar" (BENJAMIN apud MENEZES, 2004, p.38) e que, portanto, existe uma diferença entre aquilo que existe de fato no mundo e aquilo que as imagens nos mostram.

José de Souza Martins (2008b) também se posiciona contrário ao entendimento de que a fotografia, especialmente, funciona como documento de ilustração e/ou de reprodução do real. Em seu livro recente, Martins fala da responsabilidade dos sociólogos para com as imagens.

(...) ao sociólogo da imagem fotográfica põe-se o fato adicional de que a fotografia não é apenas documento para ilustrar nem apenas dado para confirmar. Não é nem mesmo e tão-somente instrumento para pesquisar. Ela é constitutiva da realidade contemporânea e, nesse sentido, é, de certo modo, objeto e também sujeito. (MARTINS, 2008b, p. 23)

Como exemplo da complexidade que envolve a análise das imagens, Martins (2008b) cita um trabalho de John Berger, que vale a pena reproduzir aqui, a respeito do estudo comparativo de fotografias de pessoas de condições sociais distintas. John Berger ${ }^{10}$ debruça-se sobre uma famosa fotografia de August Sander, intitulada Jovens Camponeses, de 1914. Se não fosse pelo nome sugestivo da foto, seríamos iludidos pela imagem de três jovens de trajes aparentemente urbanos, posando para foto numa postura imponente, produzindo, com isso, certa distinção social que os colocaria em determinada condição social que não a de um camponês ${ }^{11}$. Segundo Martins (2008b), valendo-se da interpretação demorada de Berger sobre a foto, há um "desencontro visual entre o traje (e o restante do equipamento de identificação) e o corpo", isto é, os ternos deformam o corpo dos jovens, além do que, há uma

\footnotetext{
${ }^{10}$ BERGER, John. About looking. Vintage International, New York, 1991, p.31-40, apud MARTINS, 2008b.

${ }^{11}$ Quando mostrei essa fotografia para meus alunos do Ensino Médio, numa atividade que fazemos com fotografias de fotologs, e pedi para eles descreverem o que estavam vendo, uma das alunas apressadamente disse que a imagem mostrava jovens de uma organização mafiosa, portanto, criminosos urbanos...
} 
contradição entre o ambiente (o cenário) e a vestimenta, o que constitui um "verdadeiro depoimento sobre classe social e o imaginário de classe." (MARTINS, 2008b, p.15).

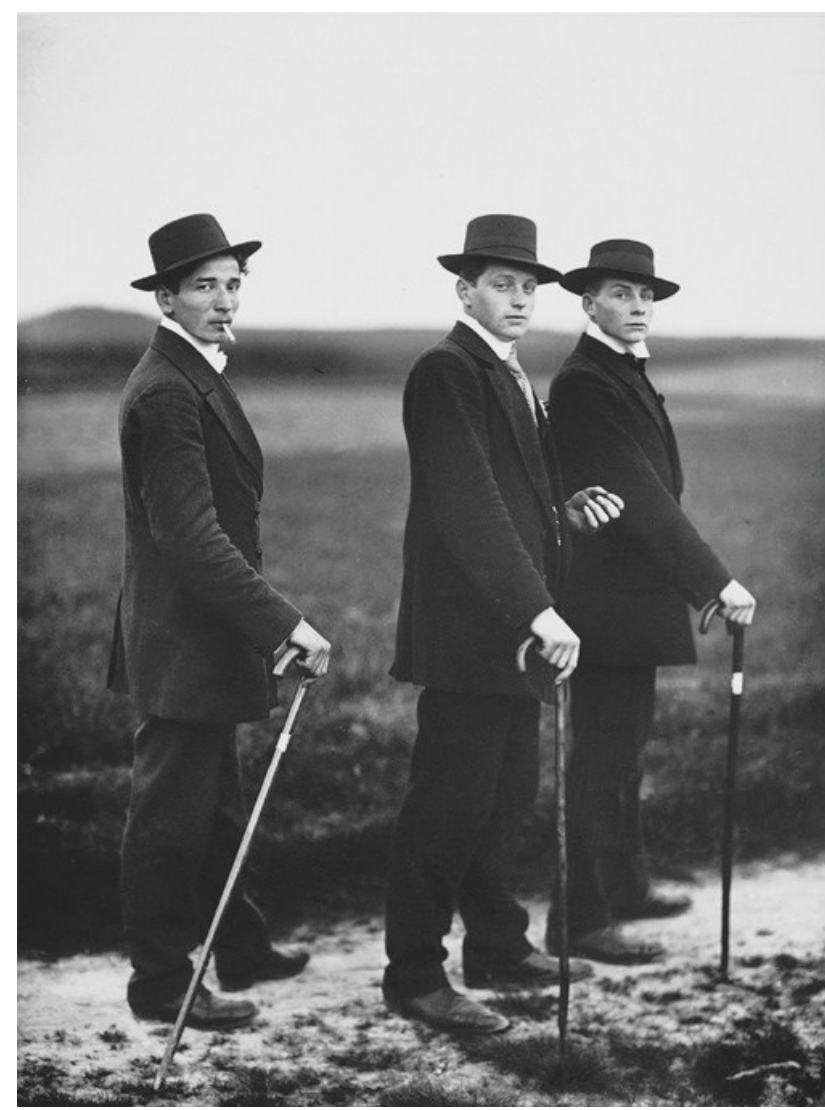

Jovens Camponeses. August Sander. 1914

A partir da fotografia de August Sander é possível perceber uma característica bastante peculiar da imagem fotográfica, conforme Martins: a de maquiar a realidade social, a de produzir encenações sobre a vida. As pessoas se representam na fotografia não como realmente são, mas como talvez gostariam de ser. Martins (2008b) nos fala da recusa ao cotidiano através da imagem, e afirma que ela se insere no imaginário da ascensão social. Por exemplo, o fato de muitas pessoas das camadas populares terem a preocupação com o ato fotográfico, levando-as a vestirse "adequadamente", a posar de determinada forma, revela o quanto as pessoas negam o seu cotidiano, a vida rotineira e repetitiva, mecanizada. Nas palavras do autor:

O trajar para ser fotografado, o traje como equipamento de identificação, cria para o fotografado uma identidade domingueira, que tenta escapar do reprodutivo, que nega o trabalho e afirma o ócio de quem vive do trabalho. Portanto, as fotografias (...) não retratam e nem documentam o cotidiano. 
Elas nos falam de uma ingênua contestação do cotidiano, sua recusa, a recusa do cotidiano como momento do trabalho. (MARTINS, 2008b, p.53).

Martins explora muito bem as "encenações" para a câmera em suas análises teóricas, como nos mostra este trecho:

\begin{abstract}
A fotografia (...) faz parte do imaginário e cumpre funções de revelação e ocultação da vida cotidiana. Portanto, as pessoas são fotografadas representando-se na sociedade e representado-se para a sociedade. (...) Ela é parte da encenação. Ela reforça a teatralidade, as ocultações, os fingimentos. Traz dignidade à falta de dignidade, ao simplismo repetitivo da vida cotidiana. (MARTINS, 2008b, p.47)
\end{abstract}

Silvia Caiuby Novaes (2004) chama a atenção para algumas relações que o(a) pesquisador(a) de imagens deve estar atento, principalmente num filme documentário ou etnográfico: "a relação entre aqueles que são filmados e a imagem que eles pretendem divulgar de si para os espectadores." (NOVAES, 2004, p.13). Ou seja, numa fotografia ou num filme documentário e mesmo etnográfico, por exemplo, em que os personagens não são atores profissionais mas atores sociais que desempenham seus próprios papéis, deve-se levar em conta, como nos sugere Novaes (2004), que "ao perceberem que estarão divulgando uma imagem para além de seus territórios, procuram elaborar esta imagem por critérios específicos." (p.13).

Nesse sentido, de acordo com Paulo Menezes (2004), devemos perceber o filme (a imagem) como parte da constituição de um imaginário social, "como expressão das formas pelas quais uma sociedade concebe-se visualmente" (p.22). E essa imagem não é mero reflexo das condições de existência, mas, ao contrário, elas tem sentido verdadeiro somente enquanto verdade fílmica (MENEZES, 2003, p.88), ou seja a imagem em sua especificidade.

É justamente nessas estratégias narrativas de construção da identidade, que só existem na própria imagem, que reside toda análise propriamente sociológica do mundo visual, ou seja, na relação que ele estabelece com o real; muito mais a realidade da imagem do que propriamente a imagem da realidade (MENEZES, 2005). Conforme Martins (2008b):

É a contradição entre o verossímil e o ilusório, e a sua unidade, que propõe a leitura sociológica possível da fotografia. Sem a referência teórica apropriada, que permita interpretar essa contradição, a fotografia, tanto na Sociologia quanto na Antropologia e na História, não passará de mera e vazia ilustração de texto. (MARTINS, 2008b, p.30)

Ulpiano Meneses (2005) também atenta para o perigo das leituras ingênuas que tentam encontrar fatos e traços do referente em imagens. 
Também acredito que as ingenuidades das leituras empíricas à cata de fatos e traços do referente (principalmente na fotografia), derivam deste mesmo campo de equívocos: proceder como se acreditasse que seus acervos documentais (principalmente fotográficos) desempenham os mesmos papéis que as coisas e eventos registrados. (MENESES, 2005, p.43)

O cineasta e documentarista brasileiro, João Moreira Salles (2005), também critica a ênfase na objetividade das concepções ingênuas. Em um artigo que trata do "problema do documentário", Salles se posiciona contrário à concepção do filme documental como "acesso não contaminado à realidade, no filme como espelho voltado para o mundo. (SALLES, 2005, p.59).

Muitos supõem que o documentário, diferente do filme ficcional, seja mais fiel à realidade do acontecimento, pois o cineasta filma aquilo que de fato ocorreu, sem se utilizar de estratégias de intervenção e comunicação com os personagens, que normalmente são pessoas comuns que desempenham seus próprios papéis. Algo muito semelhante à tradição positivista das ciências sociais, especialmente Durkheim (1995), que acreditava na neutralidade do pesquisador, da sua nãointervenção no objeto pesquisado, como pré-requisito para se entender os fatos sociais.

No entanto, Salles (2005) destaca duas naturezas do documentário:

De um lado, é o registro de algo que aconteceu no mundo; de outro lado, é narrativa, uma retórica construída a partir do que foi registrado. Nenhum filme se contenta em ser apenas registro. Possui também a ambição de ser uma história bem contada. (SALLES, 2005, p.64)

É justamente a oscilação entre documento e representação que, segundo o cineasta, constitui o verdadeiro problema do documentário. De um lado, portanto, a realidade; de outro, a imaginação autoral construída sobre a realidade, onde determinada cena não acontece naturalmente, mas é, sobretudo, construída, imaginada.

Nesse sentido, o(a) professor(a) de Sociologia que trabalha as imagens como recurso didático em suas aulas precisa estar atento para a complexidade que elas demandam e, sobretudo, problematizá-las no que elas têm de propriamente sociológico e não simplesmente tratá-las como ilustração de um determinado conteúdo ou tema trabalhado em aula, como acontece muitas vezes, conforme veremos adiante. 


\section{AS IMAGENS COMO RECURSOS DIDÁTICOS NAS AULAS DE SOCIOLOGIA}

Diante do aporte teórico descrito acima, partimos para uma análise mais objetiva dos usos da imagem nas aulas de Sociologia no Ensino Médio. Para isso, tomemos como referência os resultados obtidos com as entrevistas realizadas com professores e professoras de Sociologia de algumas escolas do País.

Para compreendermos o significado que as imagens adquirem na prática pedagógico do(a) professor(a) de Sociologia é necessário sabermos o que pensam os(s) docentes sobre a finalidade da Sociologia na escola, pois toda a prática pedagógica requer um objetivo pré-estabelecido. Quando perguntamos qual deveria ser a finalidade da Sociologia no Ensino Médio, automaticamente os professores citam o pensamento crítico, que vai para além do senso comum, uma vez que a sociologia tem a responsabilidade de compreender e explicar a sociedade, atividade esta que exige uma postura reflexiva e crítica.

\footnotetext{
A finalidade da Sociologia é desnaturalizar e historicizar as relações sociais, observar que a realidade social é construída e que deve ser transformada. (Professor Antonio) ${ }^{12}$.

Desenvolver a criticidade no discente, e tratar de temas sociais com uma perspectiva que supere o senso comum, levando o educando a pensar estas questões com outras perspectivas. (Professor Roberto)

O primeiro motivo é desenvolver o pensamento crítico, pois a maioria das outras disciplinas não tem este propósito. O outro motivo é entrar em contato com mais uma disciplina das Humanas, que exige uma maneira de pensar diferente. Exige mais leitura, interpretação... (Professora Carla).
}

Como podemos notar, o discurso dos professores em relação à finalidade da Sociologia está de acordo com os PCN's e com as atribuições dadas ao Ensino Médio pela LDB, que no seu artigo 35, inciso III, recomenda "o aprimoramento do educando como pessoa humana, incluindo a formação ética e o desenvolvimento da autonomia intelectual e do pensamento crítico" (MINISTÉRIO DA EDUCAÇÃO, LDB, grifo nosso).

Como desenvolver o "pensamento crítico" nas aulas de Sociologia a partir dos recursos visuais utilizados pelos professores? De que forma os professores trabalham a imagem em sala de aula de modo a "desnaturalizar e historizizar as

\footnotetext{
${ }^{12}$ Preservamos a identidade dos(as) professores(as) entrevistados(as) e utilizamos nomes fictícios para representá-los(as).
}

Cad. de Pesq. Interdisc. em Ci-s. Hum-s., Florianópolis, v.12, n.100, p.159-182, jan/jul 2011 
relações sociais", como afirma um dos professores entrevistados? Quais os critérios e as justificativas para a utilização da imagem em sala de aula?

O principal critério de escolha de determinado filme (ou imagem em geral) por parte dos(as) docentes é a possibilidade de relacionar os conteúdos da aula ao conteúdo do filme.

O primeiro critério é a qualidade do filme, sempre digo a eles que um filme dependendo da qualidade é uma obra de arte e, por isso, também argumento com os alunos sobre a importância de assisti-lo na língua em que foi produzido. Segundo, a abordagem sobre determinado assunto, até que ponto pode contribuir para possíveis relações com os conteúdos desenvolvidos em aula e para despertar outros temas ainda não abordados. (Professora Bruna)

Os professores argumentam que é importante relacionar o filme ao conteúdo da aula, pois o filme só é importante na medida em que desenvolve de forma mais envolvente os objetivos propostos pela disciplina. Assim, conforme a professora Carla,

O fato de estar relacionado ao conteúdo é uma preocupação que eu tenho. Pra que não pareça que a gente esteja fazendo uma coisa simplesmente diferente, só por fazer, sem nenhum motivo específico. (Professora Carla)

Assim também pensa a professora Estela:

Primeiro eu penso qual o meu objetivo na aula. Se eu vou falar sobre
racismo, eu uso o vídeo Vista a minha pele. Porque esse vídeo constrói,
nos primeiros minutos do filme... ele te leva a um pensamento sobre o que
vai aparecer, mas o filme surpreende porque ele te faz pensar sobre o
preconceito racial. Então pra mim isso é importante. Ou às vezes utilizo
filmes que os alunos não têm acesso (filmes clássicos, que não passam na
TV, que seja dinâmico, que eles consigam compreender). Então o critério é
quando o filme ajuda a elucidar o tema ou até mesmo a surpreender,
quando vai contra uma postura de senso comum. (Professora Estela)

Este é um aspecto importante do uso da imagem em sala de aula, pois a maioria dos(as) professores(as) entrevistados(as) acredita ser importante vincular o filme ao conteúdo. Isso faz do filme um instrumento de fidelidade ao real. O filme mostra ou ilustra aquilo que está no programa curricular.

No entanto, como bem afirma Ana Lucia Lucas Martins (2007), ao aceitarmos a máxima segundo a qual "a imagem vale mais do que mil palavras", estamos assim naturalizando e banalizando as imagens, como se elas fossem destituídas de significados culturais, como se elas pudessem "mostrar", de forma fiel, aquilo que o professor quer explicar. "Essa banalização estaria sustentada por um conjunto de atributos que acredita-se as imagens possuem, o poder do realismo, da precisão, do 
poder de evocar. A 'força da evidência' da fotografia seria uma questão essencial ao cientista social." (MARTINS, 2007, p.04)

Esta perspectiva fica mais evidente quando os(as) professores(as) responderam à questão sobre a forma de utilização de determinados recursos imagéticos. Foi pedido para relatarem alguma atividade com imagens em sala de aula. A perspectiva ilustrativa aparece com frequência no discurso dos(as) entrevistados(as):

Já utilizei em aulas um desenho de um livro de História onde havia a representação de um globo que tinha na parte superior pessoas de terno e gravatas fazendo festas e na inferior, pessoas com roupas humildes com vassouras nas mãos que olham para cima e questionam, trabalhei a questão das desigualdades sociais. Para discutir violência com meus alunos uma vez usei um curta-metragem em coleção sobre Ética que a escola recebeu do Programa "DVD na Escola". O curta mostrava cenas de problemas com violência no cotidiano e depois as mesmas cenas com os problemas sendo resolvidos com diálogo. Neste ano estou planejando usar dois filmes nas aulas: Ao Mestre com carinho e Planeta dos Macacos (a primeira versão), o primeiro para discutir as relações interpessoais em uma instituição e a questão da função social da escola na formação dos alunos; e, o segundo para debater as consequências da política armamentista na geopolítica mundial, e assim por diante... (Professor José).

Geralmente depois de desenvolver algum tema teórico como, por exemplo, o início do pensamento sociológico e o contexto histórico no qual aconteceu, proponho aos alunos assistirem a um filme que retrate esse momento. No desenvolvimento dos diferentes momentos do processo de produção, os filmes são formas de ajudar na compreensão e fixação dos conteúdos. Pequenos documentários sobre temas que estão sendo desenvolvidos em aula também contribuem muito, é uma linguagem que eles gostam muito. (Professora Bruna).

A partir desses depoimentos, percebe-se que a forma de utilização da imagem nas aulas de sociologia está vinculada à temática de determinado filme, fotografia ou vídeo. O racismo, as desigualdades sociais, o surgimento da sociologia, a violência, podem, segundo os professores entrevistados, ser percebidos e estudados num filme, numa imagem qualquer. O conteúdo do filme é importante porque está vinculado ao conteúdo da aula. Dessa forma, a imagem não difere muito do texto, que tradicionalmente serve para explicitar e elucidar discussões temáticas ou conceituais trabalhadas na disciplina.

Esta forma de utilização da imagem em sala de aula foi evidenciada também por Maria Adélia Alves (2001), que afirma em suas pesquisas que os(as) professores(as) parecem agir de forma transformadora ao utilizar o filme em sala de aula, mas em realidade agem da mesma forma como se estivessem usando o livro. Utilizar-se de filmes 
como sendo meros transmissores de um tema abordado, significa vê-los de uma forma "neutra", sem influências, transmissores de uma verdade, que apenas retrata de uma outra forma o conteúdo a ser estudado, visando induzir emoções. Ou seja, o que o filme mostra é considerado uma verdade a ser observada e sentida. A forma de narrar própria do filme, que possui uma linguagem, uma história, que foi produzido dentro de um contexto determinado, retratando as relações de um tempo, não é questionada e sim aceita. O que se considera é apenas a história que o filme conta e as cenas que mostra como sendo algo real, neutro, independentemente de qualquer situação, momento da produção, etc. (ALVES, 2001, p.109)

Então qual seria a importância da imagem para as aulas de Sociologia? que ela tem de diferente? Será que estamos inovando as práticas pedagógicas ao utilizarmos determinados recursos imagéticos em nossas aulas?

De acordo com os(as) entrevistados(as), a principal justificativa apresentada para o uso da imagem em sala de aula é a aproximação do aluno com a disciplina de forma "agradável", já que atualmente os filmes e as imagens em geral fazem parte da realidade cotidiana dos jovens. Vivemos em uma sociedade em que as pessoas recebem diariamente uma
grande carga de estímulos visuais; então, penso que há uma sensibilidade
nas pessoas nesse aspecto. Penso que você conseguirá melhores
resultados ao utilizar esses recursos se lembrando disso e associando os
conteúdos teóricos, os textos escritos com outros recursos que são
também fonte de conhecimento e de ensino, como é o caso do filme, do
cinema, por exemplo. O filme aí possibilita um "contato" com o mundo
empírico e torna a experiência com a Sociologia mais real. (Professora
Rita).

Acredito que eles deixam as aulas mais dinâmicas e interessantes. Os recursos diferentes do quadro e da aula expositiva simplesmente dão novas conotações ao ensino, pois acompanham o processo de transformação no próprio organismo dos alunos, falo principalmente dos adolescentes, a faixa etária com a qual trabalho. (Professor José).

Nós vivemos numa sociedade visual, em que os adolescentes estão acostumados com a tecnologia, então além de tornar as aulas um pouco mais prazerosas, ela auxilia na apreensão dos conceitos e na construção de relações. (Professor Roberto)

Dessa forma, podemos entender que a principal justificativa para o uso da imagem em sala de aula é a falta de interesse do aluno. Assim, a imagem serve para aproximá-lo do universo da disciplina, especialmente o universo dos conteúdos e dos conceitos próprios da área.

De fato, é uma justificativa que condiz com o momento presente e com as características da juventude contemporânea, extremamente "ligada" ao mundo visual. Porém está claro na fala dos(as) professores(as) que a utilização de recursos imagéticos em sala de aula pouco tem a ver com o a construção do conhecimento, e sim com a transmissão de determinados conteúdos curriculares. Mais uma vez, a 
ideia segundo a qual a imagem é equivalente ao real está presente no discurso dos(as) professores(as), que frequentemente se utilizam de um raciocínio que sinaliza o poder de evidência da imagem: ela "mostra", "revela", "retrata" "ilustra", "explica”, "auxilia”, "ajuda".

Como vimos anteriormente, a imagem não vale mais do que a palavra, ao contrário do que sugere a expressão popular. Pelo contrário, ela ilude. Ela não mostra, mas esconde. Ela não é o real, mas um modo de construir o real. Na fala dos(as) entrevistados(as), o poder de evidência das imagens é resgatado como forma de chamar a atenção dos alunos desinteressados, a fim de tornar as aulas mais "dinâmicas e interessantes" e solucionar o problema da "apatia" dos alunos e, dessa forma, conseguir abordar os temas sociológicos.

\begin{abstract}
Ao utilizarmos recursos audiovisuais tornamos visíveis e concretos alguns dos objetos de estudo das ciências sociais, levando em consideração as dificuldades de leitura e capacidade de teorização de parte considerável dos alunos. Isto auxilia no processo de compreensão dos temas abordados pela sociologia e do aprendizado. (Professor João)
\end{abstract}

Neste sentido, estamos de acordo com Alves (2001) para quem a inserção do audiovisual no espaço educacional está cumprindo outros propósitos, desvinculados do conhecimento ou da educação no sentido mais amplo.

Podemos dizer que a política de inserção do audiovisual no processo de
ensino serve a outros propósitos, não representando uma efetiva
preocupação com relação a uma pedagogia que auxilie realmente no
processo de ensino-aprendizagem do aluno, ou que permita uma maior
apreensão do conhecimento por parte deste. Não existe uma proposta
pedagógica clara nem por parte dos professores nem por parte da escola e
sua coordenação pedagógica. O uso de filmes na escola aparentemente é
sem vínculo com o conhecimento ou a educação de uma forma geral, algo
descompromissado e sem sentido claro. A única ligação com o saber é a
relação com o tema abordado, sendo o filme apenas mais uma
atividade que complementa este saber. (ALVES, 2001, p.96-97, grifo
nosso). O uso da imagem como atividade simplesmente complementar ou como estratégia para chamar a atenção do aluno acaba por reforçar o caráter tradicional da educação (NOVA, apud Alves, 2001, p. 99). Assim,

a utilização de filmes e programas de TV serviriam apenas para "animar" as aulas, dar um novo brilho a uma educação que assim revela-se vazia e sem sentido. Nestes casos "os meios são entendidos apenas como dispositivos ou instrumentos utilizados com uma finalidade meramente "instrutiva". (ALVES, 2001, p.100)

O trabalho com imagens nas aulas de Sociologia pode tornar-se muito rico dependendo da abordagem metodológica adotada pelo(a) docente. É possível perceber uma tentativa por parte dos(as) professores(as) entrevistados(as) de 
trabalhar com estes recursos de forma mais perceptiva e menos "conteudista". Isso requer um aprofundamento do trabalho com imagens que tem a ver, conforme Ana Lucia Lucas Martins (2007, p.05) com a "reflexão acerca da natureza das imagens. A imagem trabalhada cognitivamente - a que resulta do conhecimento, da consciência, do ver e do saber - aumenta a intensidade do olhar e a qualidade da imaginação." Em outras palavras,

Sejam as imagens fotográficas, fílmicas, televisivas ou informáticas a idéia é pensar que as imagens fornecem um "modo de ver" os acontecimentos, as coisas sem reduzi-la a um documento investido de um "sentimento realista". (...) É importante ainda situá-las na sua dimensão política na medida em que as convenções resultam de disputas no modo de ver as coisas em determinados contextos histórico-sociais. (MARTINS, 2007, p. 04)

Se as imagens "resultam de disputas no modo de ver as coisas", é justamente na sua especificidade, ou seja, na forma, que reside o conhecimento propriamente sociológico da imagem. Os professores entrevistados até percebem a importância da reflexão sobre a natureza das imagens, percebem que a análise sociológica do filme (e da imagem em geral) pode estar não somente no conteúdo do filme mas no próprio filme, na sua forma, ou seja, no "filme como objeto de análise". Além disso, concordam que há uma forma sociológica específica de se analisar e se trabalhar imagens e filmes em sala de aula, mas dificilmente isso se traduz em uma proposta pedagógica objetiva devido a uma reflexão metodológica tênue sobre os usos da imagem em sala de aula.

Dificilmente utilizo o filme como objeto de análise, como sugerido pela professora Ana Lucia, na oficina de ontem ${ }^{13}$. Ele é uma ilustração de um tema. Serve para falar de um assunto. Por exemplo, para discutir capitalismo e ecologia, temos o llha das Flores. Para discutir trabalho, temos o $A B C$ da Greve ou Eles não usam black-tie. Dentro da questão de gênero temos Acorda, Raimundo.(Professora Maria)

Não tenho muito conhecimento sobre essa dimensão da Sociologia, mas acho que sim, que podemos analisar filme a partir de uma perspectiva sociológica, seria uma leitura de uma leitura de mundo, uma interpretação da interpretação do cineasta. (Professor Bruna).

Portanto, como podemos perceber na fala dos(as) entrevistados(as), o uso dos recursos audiovisuais está bastante presente no espaço escolar devido a sua importância para a construção de um processo de ensino e aprendizagem mais significativos. Todavia, estas práticas carecem de uma reflexão mais aprofundada do ponto de vista metodológico e, sobretudo, sociológico, o que demonstra que os

${ }^{13}$ Oficina Imagem e Ensino de Sociologia, ministrado pela Professora Ana Lucia Lucas Martins e Amaury Moraes, no I Encontro Nacional de Ensino de Sociologia na Educação Básica, RJ, 2009.

Cad. de Pesq. Interdisc. em Ci-s. Hum-s., Florianópolis, v.12, n.100, p.159-182, jan/jul 2011 
professores necessitam de um referencial teórico e prático de trabalho, a fim de possibilitar a construção do conhecimento através das imagens. De acordo com Oliveira Jr. (apud ALVES, 2001), para além do uso instrumental dos recursos visuais, existe uma perspectiva que

\begin{abstract}
considera a própria forma de ensinar como parte do conhecimento ensinado, como integrante dele, definindo suas características e imprimindo nele suas marcas, ou seja, em que se pensa a linguagem de um conteúdo como sendo o próprio conteúdo. Ou melhor, nesta disciplina busca-se refletir sobre com que se vai apresentar tal idéia, conceito, informação, ou fato, "de forma a dar-lhe vida, em vez de celebrar sua morte". Se faremos isto com palavras, números, tabelas, fotografias, músicas, pinturas, filmes livros... (OLIVEIRA JR, apud ALVES, 2001, p.102).
\end{abstract}

Os usos das imagens em sala de aula podem contribuir muito para a imaginação sociológica numa perspectiva crítica e desnaturalizadora dos processos sociais na medida em que são utilizados como objetos de conhecimento do mundo social, e não simplesmente como estratégias "agradáveis" e "divertidas" de transmissão de conteúdos disciplinares. A educação é muito mais do que informação sobre determinado assunto. Ela é uma prática social, ou seja, uma vivência coletiva que possibilita desenvolver a imaginação e o olhar atento para o mundo, de modo a construir no sujeito as disposições sociais para um agir mais sensível, portanto, mais humano.

\title{
5 CONSIDERAÇÕES FINAIS
}

Acreditamos que o propósito da educação não é simplesmente transmitir uma carga enorme de informações baseadas em conteúdos disciplinares e curriculares, mas sim exercitar as formas de sentir o mundo a partir do olhar reflexivo. Isso traz uma nova dimensão para a educação na medida em que auxilia o sujeito na sua passagem do estado passivo em direção ao estado de alerta e de espanto, ou seja, do sujeito agido para um sujeito agente.

Como resultado da pesquisa, evidenciou-se que a imagem pode contribuir muito para o conhecimento do mundo social, no sentido desmistificador e desnaturalizador das relações sociais nas aulas de Sociologia. Mas nem sempre isso poderá se confirmar, pois depende de como o(a) professor(a) orienta 
teoricamente suas atividades no espaço escolar. Constatamos que os(as) professores(as) não tem essa orientação de forma clara, pois os recursos visuais são tratados como registro e espelho do real, ou seja, como simples ilustração dos conteúdos programáticos. Nesse sentido a imagem só é importante para os(as) professores(as) na medida em que se apresenta como apoio para a compreensão dos conteúdos trabalhados em aula ou como "estratégia" para chamar a atenção do aluno desinteressado, deixando em segundo plano a especificidade e a complexidade da mesma. Por outro lado, foi possível observar também, nas entrevistas, que há necessidade cada vez maior em se trabalhar as imagens para além dessa perspectiva ilustrativa, mas que isso não chega a se concretizar por inúmeras razões e obstáculos, dentre eles, a falta de clareza e consistência para um trabalho mais rico do ponto de vista sociológico.

Os(as) professores(as) entrevistados(as) demonstraram dificuldades em desenvolver uma abordagem propriamente sociológica da imagem. Na maioria dos casos entendem que a perspectiva sociológica está unicamente em contextualizar os conteúdos da mensagem imagética do ponto de vista histórico.

Eu não se te responder isso [sobre a análise sociológica da imagem], eu nunca parei pra pensar sobre isso. Até agora, a única análise que eu tento fazer é contextualizar do ponto de vista histórico, sempre relacionando com outras coisas.. (Professora Carla)

A análise propriamente sociológica dos recursos visuais, que possibilita o pensamento crítico e o processo de estranhamento, a nosso ver, está muito mais na forma, ou seja, na especificidade da imagem, do que no conteúdo que ela transmite. $\mathrm{Na}$ definição de Ulpiano Bezerra de Meneses (2005), está muito mais na realidade da imagem do que propriamente na imagem da realidade. Forma e conteúdo são inseparáveis. Desse modo podemos conhecer a vida em sociedade partindo da sua interpretação visual, em que a própria imagem é o objeto principal que possibilitará o desenvolvimento do olhar sociológico, sem necessariamente estar vinculada a informações redutíveis a um conteúdo ou tema específicos. Assim, os resultados parciais que esta pesquisa apresenta estão de acordo com a perspectiva de Ana Lúcia Lucas Martins, quando afirma que

O uso de filmes em sala de aula não tem como propósito a busca de correspondência entre fatos e representações imagéticas. Deve-se pensar que filmes são um modo pelo qual pessoas, no caso, cineastas, expressam suas idéias, concepções de mundo sobre temas, problemas da realidade, gerando um outro modo de conhecer que é dado através da maneira como as sociedades se produzem visualmente. (MARTINS, 2007, p. 08) 
Sendo assim, é importante tomar as imagens como método de análise, ou seja, como objeto de conhecimento do mundo social, sem confundi-las com o mundo propriamente dito. A imagem não tem a realidade como ponto de referência, portanto, ela não serve como ilustração ou demonstração de conteúdos nas aulas de Sociologia. Conforme Benjamin (1986), a imagem diz muito pouco sobre o acontecido; ela tem referência na cultura e no imaginário social. Deixar-se levar pelo mundo fantasioso das imagens na cotidianidade contemporânea é o mesmo que aceitá-lo como mundo pretensamente natural, desprovido de historicidade concreta. Em outras palavras, não devemos confundir o real com o virtual, muito menos substituir o real pelo virtual. Cabe ao docente, portanto, problematizar as imagens na sua forma de representar a realidade. Isso tem a ver com a construção do pensamento crítico, uma das finalidades da Sociologia na escola.

Acreditamos que este trabalho, pautado nos estudos da Sociologia do Conhecimento Visual, pode oferecer subsídios importantes para a formação pedagógica dos professores e professoras de Sociologia. Para que os recursos visuais não caiam no vazio das práticas pedagógicas irrefletidas, esta pesquisa pode servir como orientação para o processo qualificado de formação de professores para o ensino médio. 


\section{REFERÊNCIAS}

ALVES, Maria Adélia. Filmes na Escola: uma abordagem sobre o uso de audiovisuais (vídeo, cinema e programas de TV) nas aulas de Sociologia do Ensino Médio. 2001. Dissertação de Mestrado. Universidade Estadual de Campinas Unicamp, Faculdade de Educação, São Paulo, 2001.

AUMONT, Jacques. A Imagem. Campinas, São Paulo: Papirus, 1993.

BARTHES, Roland. O óbvio e o obtuso: ensaios críticos III. Rio de Janeiro: Nova Fronteira, 1990.

BAZIN, André. A ontologia da imagem fotográfica. In: BAZIN, André. O Cinema: ensaios. São Paulo: Editora Brasiliense, 1991. p.19-26.

BECKER, Howard. Explorando a sociedade fotograficamente. Cadernos de Antropologia e Imagem, n.2, p. 95-98, 1996,

FRANCASTEL, Pierre. Imagem, visão e imaginação. Lisboa: Edições 70, 1987.

HIKIJI, Rose Satiko. Possibilidades de uma audição da vida social. In: MARTINS, José de Souza; ECKERT, Cornélia; NOVAES, Silvia Caiuby (orgs.). O Imaginário e o Poético nas Ciências Sociais. São Paulo: Edusc, 2005. p.271-294.

KOURY, Mauro Guilherme Pinheiro. A imagem nas ciências sociais do Brasil: um balanço crítico. Revista Brasileira de Informação Bibliográfica em Ciências Sociais, Rio de Janeiro, v.47, p. 49-64, 1999.

KOURY, Mauro Guilherme. Estado das artes nas ciências sociais do visual no Brasil. Política \& Trabalho, João Pessoa, v.14, p. 91-110, 1998.

MARTINS, Ana Lucia Lucas. Cinema e Ensino de Sociologia: usos de filmes em sala de aula. In: CONGRESSO BRASILEIRO DE SOCIOLOGIA, 13, 2007, Recife.

Anais... Recife: UFPE, 2007.

MARTINS, José de Souza. A peleja da vida cotidiana em nosso imaginário onírico. In: MARTINS, José de Souza. (Des)figurações: a vida cotidiana no imaginário onírico da metrópole. São Paulo: Hucitec, 1996, p.15-72. 
MARTINS, José de Souza. Sociologia da Fotografia e da Imagem. São Paulo: Contexto, 2008b.

MARTINS, José de Souza; ECKERT, Cornélia; NOVAES, Sylvia Caiuby (orgs.). 0 Imaginário e o poético nas Ciências Sociais. São Paulo: Edusc, 2005.

MENESES, Ulpiano Bezerra. Rumo a uma História visual. In: MARTINS, José de Souza; ECKERT, Cornélia; NOVAES, Silvia Caiuby (orgs.). 0 Imaginário e o Poético nas Ciências Sociais. São Paulo: Edusc, 2005, p.33-56.

MENEZES, Paulo. O Cinema Documental como Representificação: verdade e mentiras nas relações (im)possíveis entre representação, documentário, filme etnográfico, filme sociológico e conhecimento. In: NOVAES, Silvia Caiuby et al. Escrituras da Imagem. São Paulo: FAPESP, 2004. p.21-48.

MENEZES, Paulo. O nascimento do cinema documental e o processo não civilizador. In: MARTINS, José de Souza; ECKERT, Cornélia; NOVAES, Silvia Caiuby (orgs.). O Imaginário e o Poético nas Ciências Sociais. São Paulo: Edusc, 2005. p.73-127.

MENEZES, Paulo. Representificação: as relações (im)possíveis entre cinema documental e conhecimento. Revista Brasileira de Ciências Sociais, v.18, n.51, fevereiro de 2003. p.87-97.

MIGUEL, Jesus de. El ojo sociológico. Reis - Revista española de investigaciones sociológicas, n.101, p.49-88, 2003.

MIGUEL, Jesus de; LEÓN, Omar G. Ponce. Para una sociología de la fotografía. Reis - Revista española de investigaciones sociológicas, n.84, p.84-124, out/dez 1998.

MINISTÉRIO DA EDUCAÇÃO. Lei de Diretrizes e Bases da Educação Nacional. Lei n 9.394/1996. Brasília. Disponível em:

<http://www.planalto.gov.br/ccivil 03/LEIS/I9394.htm> . Acesso em: 25 abr 2009.

MOURA, Lisandro L. L. Imagem e Conhecimento: a educação do olhar no ensino da Sociologia no Ensino Médio. 2010. Trabalho de Conclusão de Curso ( Bacharel em Ciências Sociais) Instituto de Filosofia e Ciências Humanas, Departamento de Sociologia, Universidade Federal do Rio Grande do Sul - UFRGS, 2010. 
MOURA, Lisandro Lucas de Lima; GUIMARÃES, Rodrigo Belinaso. Pensando Conteúdos e Metodologias em Sala de Aula: a experiência da Sociologia no Colégio de Aplicação da UFRGS. Cadernos do Aplicação, v.22, n.1, 2009.

NOVAES, Silvia Caiuby. Imagem em Foco nas Ciências Sociais. In: NOVAES, Silvia Caiuby et al. Escrituras da Imagem. São Paulo: FAPESP, 2004. p.11-18.

SALLES, João Moreira. A dificuldade do documentário. In: MARTINS, José de Souza; ECKERT, Cornélia; NOVAES, Silvia Caiuby (orgs.). O Imaginário e o Poético nas Ciências Sociais. São Paulo: Edusc, 2005, p.57-71.

SONTAG, Susan. Sobre a fotografia. Companhia das Letras: São Paulo, 2004.

Artigo:

Recebido em: 21/03/2011

Aceito em: 06/06/2011 